\title{
Implementasi fuzzy weighted product penyusunan aksi rehabilitasi rekonstruksi pasca bencana berbasis decision support system dynamic
}

\author{
Agung Teguh Wibowo Almais ${ }^{1}$, Fatchurrochman ${ }^{2}$ \\ 1,2 Jurusan Teknik Informatika, UIN Maulana Malik Ibrahim Malang
}

Informasi Artikel

Riwayat Artikel

Diterima 25 Februari 2020

Direvisi 20 Maret 2020

Diterbitkan 28 April 2020

Kata kunci:

DSSD

F-WP

Data pola

Data Uji

Surveyor

Keywords:

DSSD

F-WP

Pattern data

Test data

Surveyor

\begin{abstract}
ABSTRAK
Penyusunan aksi rehabilitasi rekonstruksi pasca bencana alam dilakukan untuk mengetahui jenis kerusakan dan besarnya kerugian pasca bencana alam yang harus ditanggung pemerintah. Agar jenis kerusakan dan besarnya kerugian pasca bencana alam sesuai data yang dilapangan maka dilakukan penelitian yang mengimplementasikan Decision Support System Dynamic (DSSD) dengan metode FuzzyWeighted Product (F-WP). Hasil dari pengujian menghasilkan tiga jenis data yang berbeda yaitu data uji yang sama dengan data pola, data uji yang tidak sama dengan data pola, dan data uji yang tidak bisa diterpakan untuk pengujian. Masing-masing jenis data uji tersebut memilik prosentase yaitu $73 \%$ data uji yang sama dengan data pola, $22 \%$ data uji yang tidak sama dengan data pola, dan 5\% merupakan data yang tidak dapat digunakan sebagai data uji. Dari hasil pengujian tersebut dapat disimpulkan bahwa metode Fuzzy-Weighted Product (F-WP) dapat diterapkan pada Decision Support System Dynamic (DSSD) untuk membantu surveyor dalam melakukan penyusunan aksi rehabilitasi rekonstruksi pasca bencana alam.
\end{abstract}

\begin{abstract}
Preparation of rehabilitation reconstruction actions after natural disasters is carried out to determine the types of damage and the number of losses after natural disasters that must be borne by the government. So that the type of damage and the magnitude of losses after natural disasters match the data in the field, a study is carried out that implements a Decision Support System Dynamic (DSSD) with the Fuzzy-Weighted Product (F-WP) method. The results of tests produce three types of data that are different, namely the same test data with pattern data, test data that are not the same as pattern data, and test data that cannot be applied for testing. Each type of test data has a percentage that is $73 \%$ of the same test data like the pattern data, $22 \%$ of the test data are not the same as the pattern data, and 5\% are data that cannot be used as test data. From the test results it can be concluded that the Fuzzy-Weighted Product (F-WP) method can be applied to the Decision Support System Dynamic (DSSD) to assist surveyors in carrying out the rehabilitation reconstruction actions after natural disasters.
\end{abstract}

\section{Penulis Korespondensi:}

Agung Teguh Wibowo Almais, Jurusan Teknik Informatika, UIN Maulana Malik Ibrahim Malang, J1. Gajayana No. 50, Malang, Jawa Timur, Indonesia.

Email: agung.twa@gmail.com / agung.twa@ti.uin-malang.ac.id 


\section{PENDAHULUAN}

Penyusunan aksi rehabilitasi dan rekonstruksi merupakan salah satu hal yang harus dilakukan oleh salah satu tim yang ada di Badan Penanggulanan Bencana Daerah (BPBD) yaitu Tim Perencanaan dan Pengendalian Penanganan Bencana (P3B) untuk menentukan tingkat kerugian dan kerusakan sektor yang terdampak bencana alam, dengan mengetahui tingkat kerugian dan kerusakan tersebut maka akan mudah dalam menyusun aksi rehabilitasi dan rekonstruksi pasca bencana untuk menentukan besarnya bantuan yang harus disalurkan kepada korban yang terdampak bencana alam [1]. Pada penelitiannya [2] dijelaskan bahkan untuk menentukan tingkat kerusakan dan kerusakan sektor akibat bencana alam adalah menggunakan sebuah acuan yang disebut ECLAC (Economic Commission for Latin America and Caribbean). Pada jurnal tersebut telah dijelaskn bahwa ECLAC telah digunakan oleh pemerintah Indonesia untuk menghitung kerugian dan kerusakan pada gempa bumi di daerah istimewa Yogyakarta tahun 2006 dan tsunami di daerah istimewa Aceh. Menurut Kadarsah dalam tulisan [3] untuk melakukan penelitian tentang Decision Support System banyak persyaratan yang harus dipenuhi diantaranya masalah yang dibahas harus memiliki tingkat kompleksitasnya yang tinggi dan semi terstruktur.

Kekompleksitasan pada penelitian pada jurnal ini yaitu bagaimana menentukan tingkat kerusakan dan kerugian sektor daerah yang terdampak bencana alam agar sesuai dengan kondisi sebenarnya di daerah yang terdampak bencana alam [4]. Selama ini kerugian dan kerusakan sektor yang terdampak bencana alam dilakukan oleh tim P3B yaitu surveyor [1]. Surveyor akan menentukan kondisi sektor yang terdampak bencana alam dengan pengetahuan mereka [4]. Pada penelitiannya [1] bahwa pemerintah melalui (kementrian PU) memiliki kriteria untuk menentukan rumah atau bangunan tahan gempa bencana alam. Kriteria-kriteria tersebut yaitu 1). Keadaan bangunan 2). Keadaan struktur bangunan 3). Keadaan fisik bangunan rusak sebesar 4). Fungsi bangunan 5). Keadaan penunjang lainnya, sehingga dari kriteria tersebut dapat digunakan sebagai acuan mengembangkan sebuah penelitian di bidang Decision Support System untuk membantu pemerintah (surveyor) untuk membangun sebuah sistem berbasis komputer yang dapat membantu menentukan tingkat kerusakan dan kerugian sektor yang terdampak bencana alam.

Dengan menggunakan kriteria yang ada pada peneiltian tersebut maka dapat menggunakan metode Multi Criteria Decision Making, karena metode Multi Criteria Decision Making merupakan suatu metode yang digunakan untuk memecahkan suatu sistem pendukung keputusan berdasarkan alternatif dan kriteria yang sudah ditentukan pada masing-masing permasalahan yang akan diselesaikan [1]. Dengan menggunakan fuzzy diharapkan dapat melakukan pembobotan kriteria dan melakukan penilaian alternatif dengan lebih bagus karena dengan fuzzy dapat menjadikan suatu skala pembobotan dan penilaian menjadi bilangan crisp yang lebih mudah dipahami oleh pengguna. Pada saat pembobotan kriteria dan penilaian alternatif berdasarkan kriteria maka bobot dan nilai tersebut mengggunakan bilangan fuzzy yang kemudian akan dikonversi ke bilangan cirsp agar dapat dihitung menggunakan metode Multi Criteria Decision Making [5].

\section{METODE PENELITIAN}

\subsection{Fuzzy Weigted Product (F-WP)}

Menurut [5] metode Weighted Product merupakan rumus klasik dari metode Multi Criteria Decision Making. Untuk mengembangkan metode tersebut perlu di kembangkan dengan penambahan metode fuzzy agar metode Multi Criteria Decision Making (Weighted Product) dapat membedakan penggunaan skala penilaian setiap kriteria yang sesuai dengan kriteria masing-masing. Metode Weighted Product menggunakan perkalian untuk menghubungkan rating attribut, dimana rating setiap attribut harus dipangkatkan dulu dengan bobot attribut yang bersangkutan [6]. Proses ini sama halnya dengan proses normalisasi. Preferensi untuk alternatif diberikat sebagai berikut:

$$
S_{i}=\prod_{j=1}^{n} x_{i j}^{w_{j}} ; \text { dengan } \mathrm{i}=1,2, \ldots . ., \mathrm{m} .
$$

Dimana $\sum w_{j}=1 w_{j}$ merupakan pangkat yang bernilai positif jika digunakan untuk atribute keuntungan dan bernilai negatif jika digunakan untuk atribut biaya.

Sedangkan untuk mencari preferensi relatif dari setiap alternatif menggunakan persamaan (2) sebagai berikut:

$$
V_{i}=\frac{\prod_{j=1}^{n} x_{i j}^{w_{j}}}{\prod_{j=1}^{n}\left(x_{j}^{*}\right)^{w_{j}}} ; \text { dengan } \mathrm{i}=1,2, \ldots, \mathrm{m} .
$$

Pengimplementasian fuzzy pada metode Weighted Product digunakan sebagai skala penilaian untuk setiap kriteria yang digunakan pada metode Weighted Product. Seperti penjelasan diatas terdapat 5 kriteria dan masingmasing kriteria memiliki skala penilaian masing-masing. Skala penilaian setiap kriteria memiliki value (nilai) masingmasing seperti yang sudah dijelaskan diatas. Jika bilangan fuzzy dengan kriteria yang digunakan pada metode Weighted Product dibuat tabel, maka akan seperti pada tabel 1 dibawah ini: 
Tabel 1. Skala penilaian kriteria

\begin{tabular}{|c|c|c|c|}
\hline No. & Kriteria & Skala Penilaian kriteria & Value \\
\hline \multirow[t]{3}{*}{1.} & \multirow{3}{*}{$\begin{array}{l}\text { Keadaan } \\
\text { Bangunan }\end{array}$} & Masih Berdiri & $0-0.33$ \\
\hline & & Miring & $0.33-0.66$ \\
\hline & & Roboh Total & $0.66-1$ \\
\hline \multirow[t]{3}{*}{2.} & \multirow{3}{*}{$\begin{array}{l}\text { Keadaan } \\
\text { Struktur } \\
\text { Bangunan }\end{array}$} & Sebagian Kecil Rusak Ringan & $0-0.33$ \\
\hline & & Sebagian Kecil Rusak & $0.33-0.66$ \\
\hline & & Sebagian Besar Rusak & $0.66-1$ \\
\hline \multirow[t]{4}{*}{3.} & \multirow{4}{*}{$\begin{array}{l}\text { Kondisi } \\
\text { Fisik } \\
\text { Bangunan } \\
\text { Rusak } \\
\text { Sebesar }\end{array}$} & $<30 \%$ & $0-0.33$ \\
\hline & & $30-50 \%$ & $0.33-0.66$ \\
\hline & & & \\
\hline & & $>50 \%$ & $0.66-1$ \\
\hline \multirow[t]{3}{*}{4.} & \multirow{3}{*}{$\begin{array}{l}\text { Fungsi } \\
\text { Bangunan }\end{array}$} & Tidak Berbahaya & $0-0.33$ \\
\hline & & Relatif Bahaya & $0.33-0.66$ \\
\hline & & Membahayakan & $0.66-1$ \\
\hline \multirow[t]{3}{*}{5.} & \multirow{3}{*}{$\begin{array}{l}\text { Keadaan } \\
\text { Penunjang } \\
\text { Lainnya }\end{array}$} & Sebagian Kecil Rusak & $0-0.33$ \\
\hline & & Sebagian Besar Rusak & $0.33-0.66$ \\
\hline & & Rusak Total & $0.66-1$ \\
\hline
\end{tabular}

\subsection{Metode}

Terdapat 5 kriteria yang digunakan untuk menentukan tingkat kerusakan dan kerusakan sektor pasca bencana alam menurut jurnal [1] yaitu:

\begin{tabular}{ll}
\hline No & Nama Kriteria \\
\hline 1 & Keadaan Bangunan \\
2 & Keadaan Struktur Bangunan \\
3 & Kondisi Fisik Bangunan Rusak Sebesar \\
4 & Fungsi Bangunan \\
5 & Keadaan Penunjang Lainnya \\
\hline
\end{tabular}

Setiap kriteria pada tabel 2 diatas memiliki skala masing-masing. Dengan menggunakan fuzzy maka skala setiap kriteria dapat ditentukan dengan mengkonversi bilangan fuzzy yang ada ke bilangan crisp pada setiap kriteria yang ada pada tabel 1 diatas.

a. Skala Penilaian Keadaan Bangunan

Untuk kriteria keadaan bangunan memiliki tiga jenis skala penilaian yaitu Masih berdiri, Miring dan Roboh Total. Masing-masing skala penilaian tersebut batas memiliki value sendiri-sendiri. Untuk skala penilaian Masih Berdiri memiliki value 0 - 0.33 , untuk skala penilaian Miring memiliki value $0.33-0.66$ dan untuk skala penilaian Roboh Total memiliki value 0.66 - 1 . Untuk lebih jelasnya dapat dilihat pada gambar 1 dibawah ini.

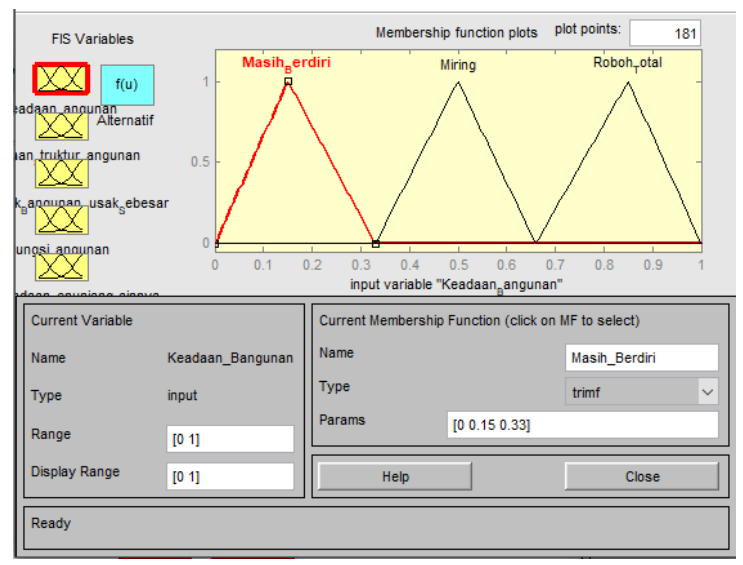

Gambar 1. Skala penilaian keadaan bangunan 
b. Skala Penilaian Keadaan Struktur Bangunan

Untuk kriteria Keadaan Struktur Bangunan memiliki tiga jenis skala penilaian yaitu Sebagian Kecil Rusak Ringan, Sebagian Kecil Rusak dan Sebagian Besar Rusak. Masing-masing skala penilaian tersebut batas memiliki value sendiri-sendiri. Untuk skala penilaian Sebagian Kecil Rusak Ringan memiliki value 0 - 0.33, untuk skala penilaian Sebagian Kecil Rusak memiliki value 0.33 - 0.66 dan untuk skala penilaian Sebagian Besar Rusak memiliki value 0.66 - 1. Untuk lebih jelasnya dapat dilihat pada gambar 2 dibawah ini.

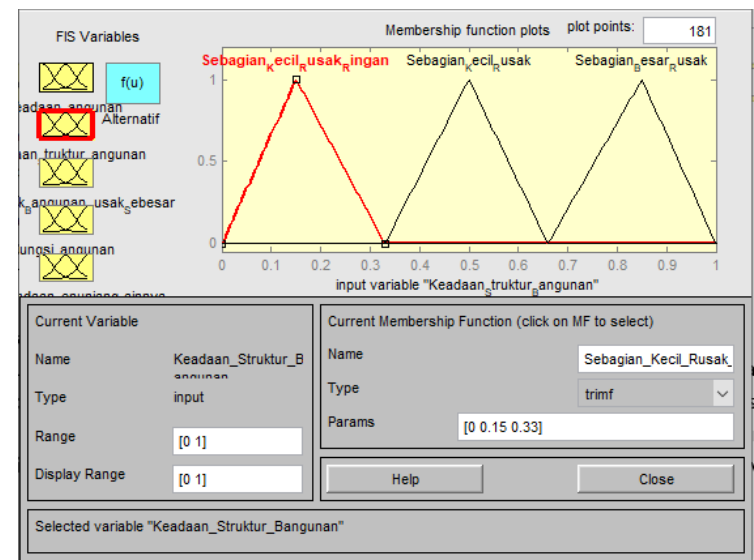

Gambar 2. Skala Penilaian Keadaan Struktur Bangunan

c. Skala Penilaian Kondisi Bangunan Rusak Besar

Untuk kriteria Kondisi Bangunan Rusak Besar memiliki tiga jenis skala penilaian yaitu <30\%, 30-50\% dan $>50 \%$. Masing-masing skala penilaian tersebut batas memiliki value sendiri-sendiri. Untuk skala penilaian $<30 \%$ memiliki value $0-0.33$, untuk skala penilaian $30-50 \%$ memiliki value $0.33-0.66$ dan untuk skala penilaian $>50 \%$ memiliki value $0.66-1$. Untuk lebih jelasnya dapat dilihat pada gambar 3 dibawah ini.

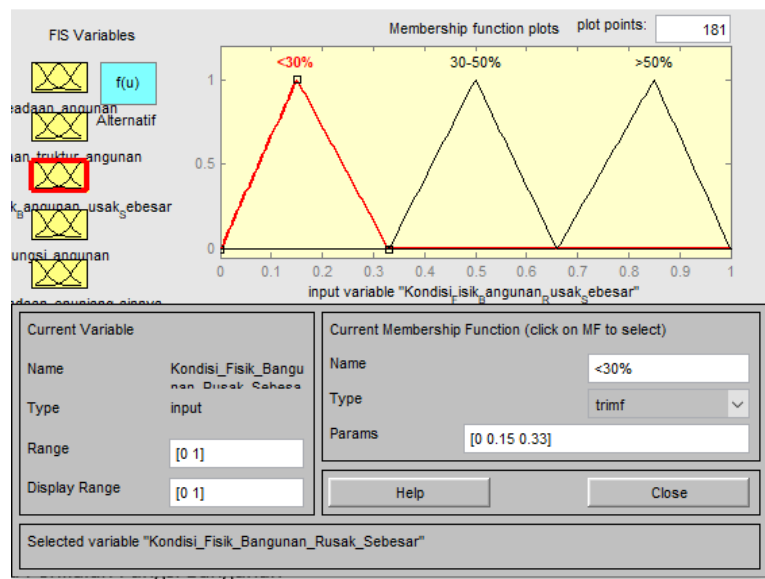

Gambar 3. Skala penilaian Kondisi Bangunan Rusak Besar

d. Skala Penilaian Fungsi Bangunan

Untuk kriteria Fungsi Bangunan memiliki tiga jenis skala penilaian yaitu Tidak Berbahaya, Relatif Bahaya dan Membahayakan. Masing-masing skala penilaian tersebut batas memiliki value sendiri-sendiri. Untuk skala penilaian Tidak Berbahaya memiliki value 0 - 0.33, untuk skala penilaian Relatif Bahaya memiliki value 0.33 0.66 dan untuk skala penilaian Membahayakan memiliki value $0.66-1$. Untuk lebih jelasnya dapat dilihat pada gambar 4 dibawah ini. 


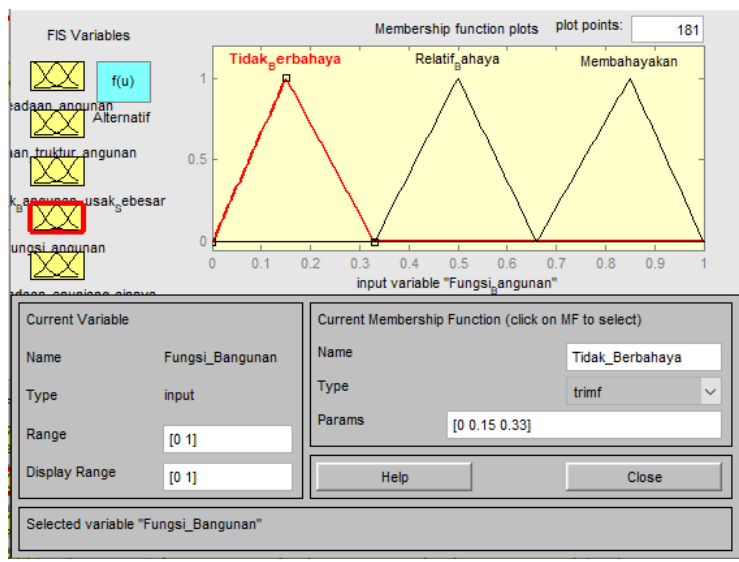

Gambar 4. Skala penilaian Fungsi Bangunan

e. Skala Penilaian Keadaan Penunjang Lainnya

Untuk kriteria Kondisi Bangunan Rusak Besar memiliki tiga jenis skala penilaian yaitu Sebagian Kecil Rusak, Sebagian Besar Rusak dan Rusak Total. Masing-masing skala penilaian tersebut batas memiliki value sendirisendiri. Untuk skala penilaian Sebagian Kecil Rusak memiliki value 0 - 0.33, untuk skala penilaian Sebagian Besar Rusak memiliki value 0.33 - 0.66 dan untuk skala penilaian Rusak Total memiliki value $0.66-1$. Untuk lebih jelasnya dapat dilihat pada gambar 5 dibawah ini.

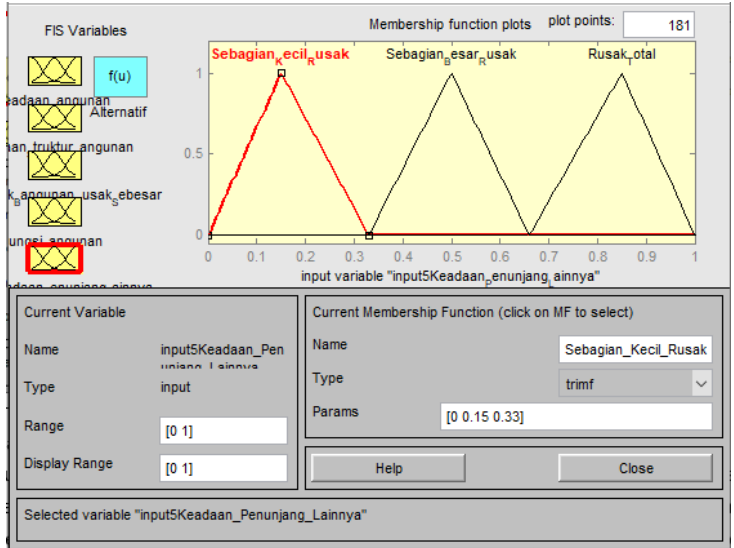

Gambar 5. Skala penilaian Keadaan Penunjang Lainnya

Skala diatas digunakan untuk melakukan penilaian dan pembobotan untuk setiap kriteria. Jika diimplementasikan dalam bentuk sistem seperti gambar 6 dibawah ini;

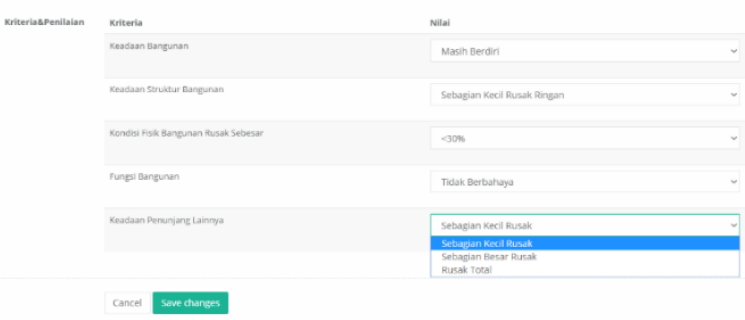

Gambar 6. Implementasi Fuzzy - Weighted Product (F-WP)

\section{HASIL DAN PEMBAHASAN}

Pada penelitian ini terdapat dua jenis data yaitu data pola dan data uji. Data pola digunakan untuk membentuk suatu pola data menggunakan metode Fuzzy-Weighted Product $(F-W P)$, sedangkan data uji digunakan untuk menguji data pola yang telah dibangun. Data pola merupakan hasil perhitungan Fuzzy-Weighted Product (F-WP), menggunakan data kerusakan dan kerugian pasca bencana provinsi Jawa Timur tahun 2010-2013. Hasil dari data pola tersebut merupakan sebuah hasil jenis kerusakan dan kerugian masing-masing sektor (Rusak Ringan, Rusak Sedang, dan Rusak Berat).

Implementasi fuzzy weighted product penyusunan aksi rehabilitasi rekonstruksi pasca bencana berbasis decision support system dynamic (Agung Teguh Wibowo Almais) 
Hasil dari data pola tersebut akan diuji menggunakan data kerusakan dan kerugian pasca bencana provinsi Jawa Timur tahun 2018. Untuk data uji hanya menggunakan kriteria dan penilaian masing-masing kriteria untuk mendapatkan hasil jenis kerusakan dan kerugian masing-masing sektor (Rusak Ringan, Rusak Sedang, dan Rusak Berat). Hasil dari data uji akan dicari di data pola yang sudah dibuat. Jika saat menggunakan data uji, data uji tersebut tidak ada pada data pola maka akan secara otomatis data uji tersebut menghitung sendiri dengan menggunakan metode Fuzzy-Weighted Product (F-WP). Untuk lebih jelasnya cara mencari atau mencocokkan data uji dengan data pola yang ada di sistem, dapat dilihat pada gambar 7 berikut:

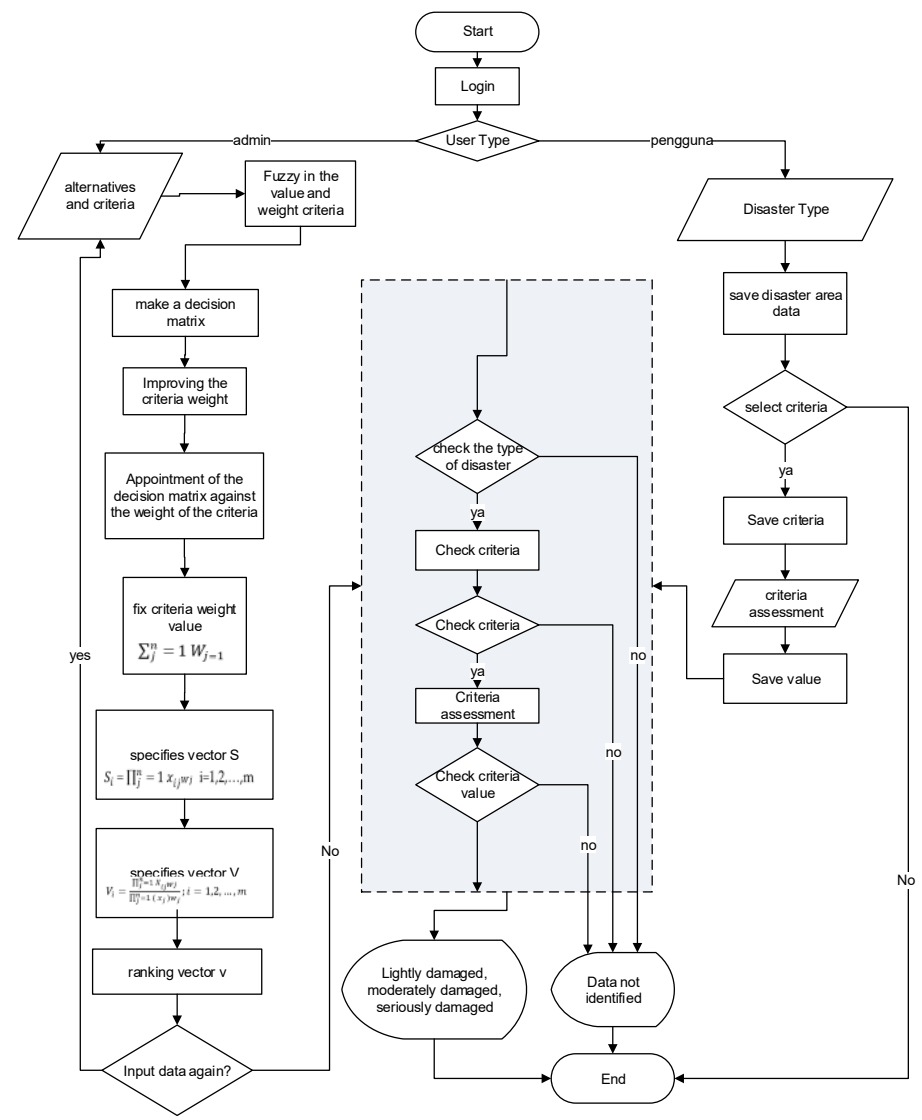

Gambar 7. Alur system

Pengujian dilakukan dengan menghitung jumlah data uji yang dapat digunakan untuk melakukan uji coba. Selain menghitung data uji yang dapat di gunakan pengujian, juga dihitung data yang tidak dapat digunakan untuk pengujian. Komposisi data uji terlihat seperti tabel 3 dibawah ini.

Tabel 3. Komposisi data

\begin{tabular}{lccccc}
\hline Metode & $\begin{array}{c}\text { Data } \\
\text { Pola }\end{array}$ & \multicolumn{3}{c}{ Data Uji } \\
\cline { 2 - 6 } & $\begin{array}{c}\text { Jumlah } \\
\text { Data }\end{array}$ & $\begin{array}{c}\text { Jumlah } \\
\text { Data }\end{array}$ & $\begin{array}{c}\text { Data } \\
\text { yang } \\
\text { sama }\end{array}$ & $\begin{array}{c}\text { Data } \\
\text { yang } \\
\text { tidak } \\
\text { sama }\end{array}$ & $\begin{array}{c}\text { Data yang tidak } \\
\text { teridentifikasi }\end{array}$ \\
& & & & & \\
\hline $\begin{array}{l}\text { Fuzzy- } \\
\text { WP }\end{array}$ & 85 & 204 & 148 & 45 & 11 \\
\hline
\end{tabular}


Hasil pengujian dari data uji tersebut akan dihitung menggunakan perhitungan confusion matrix (accuracy, f-measure, recall, dan precision) untuk masing-masing hasil dari data uji yang digunakan. Jumlah data yang digunakan untuk menjadi data pola dan data uji jumlahnya berbeda. Seperti terlihat pada tabel 3 diatas merupakan list dari jumlah data yang digunakan pada data pola dan data uji.

Pada tabel 3 diatas terlihat bahwa data uji yang telah digunakan pengujian data pola menghasilkan tiga jenis data yang memiliki jumlah yang berbeda-beda yaitu data yang sama (data yang dapat menghasilkan data sama dengan data pola dengan jumlah 148 data), data yang tidak sama (data yang menghasilkan data tidak sama dengan data pola dengan jumlah 45 data), dan data yang tidak teridentifikasi (data yang tidak dapat digunakan untuk data pengujian karena memiliki kriteria yang tidak dapat diidentifikasi). Untuk lebih jelasnya hasil perhitungan data uji dengan data pola dapat dilhat pada tabel 4 dan gambar 9 dibawah ini.

Tabel 4. Hasil Pengujian Metode Fuzzy-Weighted Product (F-WP)

\begin{tabular}{lll}
\hline Metode Pengujian & Percobaan & Average \\
\hline Precision & $76.68 \%$ & $76.68 \%$ \\
\hline Recall & $93.08 \%$ & $93.08 \%$ \\
\hline Accuracy & $73.95 \%$ & $73.95 \%$ \\
\hline F-Measure & $84.09 \%$ & $84.09 \%$ \\
\hline
\end{tabular}

\title{
HASIL UJICOBA SISTEM PENDUKUNG KEPUTUSAN AKSI REHABILITASI DAN REKONSTRUKSI PASCA BENCANA
}

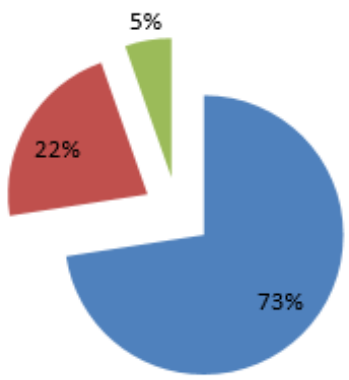

\author{
- DATA YANG SAMA \\ DATA YANG TIDAK SAMA \\ - DATA YANG TIDAK \\ TERIDENTIFIKASI
}

Gambar 9. Hasil Pengujian

\section{KESIMPULAN}

Metode Fuzzy-Weighted Product dapat digunakan untuk membantu surveyor untuk penyusunan aksi rehabilitasi rekonstruksi pasca bencana alam. Dengan menggunakan data pola dan data uji yang diterapkan pada pemodelan Decision Support System Dynamic (DSSD), mampu menghasilkan 3 jenis data berbeda yaitu data uji yang sama dengan data pola, data uji yang tidak sama dengan data pola, dan data uji yang tidak dapat digunakan untuk pengujian sistem. Tiga jenis data tersebut memiliki prosentase yang berbeda-beda yaitu $73 \%$ data uji yang sama dengan data pola, $22 \%$ data uji yang tidak sama dengan data pola, dan 5\% merupakan data yang tidak dapat digunakan sebagai data uji. Hasil dari jurnal ini diharapkan bisa menjadi acuan penelitian selanjutnya dengan menggabungkan metode Artificial Intelligent (AI) lainnya atau menggunakan metode Multi Criteria Decision Making (MCDM) yang modern agar mendapatkan perbedaan hasil yang lebih baik dan pengembangan ilmu.

\section{DAFTAR PUSTAKA}

[1] A. T. W. Almais, M. Sarosa e M. A. Muslim, "Implementation Of Multi Expert Multi Criteria Decision Making Form Rehabilitation and Rekonstruction action After a Disaster," MATICS, pp. 27-31, 2016.

[2] F. Oetari, S. Y. JP e A. Nugroho, "Pengembangan Sistem Informasi Penilaian Kerusakan dan Kerugian Bencana Menggunakan Metode ECLAC (Economic Commission for Latin America and Caribbean) (Studi Kasus Erupsi Gunung Merapi 2010 di Kab. Boyolali),” Aiti, pp. 169-183, 2014.

[3] K. Suryadi, Sistem Pendukung Keputusan Suatu Wacana Struktural Idealisasi Dan Implementasi Konsep Pengambilan Keputusan., Bandung: Remaja Rosdakarya, 2014.

Implementasi fuzzy weighted product penyusunan aksi rehabilitasi rekonstruksi pasca bencana berbasis decision support system dynamic (Agung Teguh Wibowo Almais) 
[4] A. Bachriwindi, E. Putra, U. Munawaroh e A. Almais, "Implementation of Web-Based Weighted Product Use Decision Support System to Determine the Post-Disaster Damage and Loss," ICE_ELINVO, p. 012019, 11 2019.

[5] S. Kusumadewi, S. Hartati, A. Harjoko e R. Wardoyo, Fuzzy Multi-Attribute Decision Making (FUZZY MADM), Yogyakarta: Graha Ilmu, 2006.

[6] Yoon, Fuzzy Multi-Attribute Decision Making (FUZZY), Yogyakarta, 1989. 